\title{
Adapting to Climate Extreme Events Based on Livelihood Strategies: Evidence from Rural Areas in Thua Thien Hue Province, Vietnam
}

\author{
Dao Duy Minh ${ }^{1,2, * \mathbb{C}}$, Nguyen Dang Hao ${ }^{3}$ and Philippe Lebailly ${ }^{2}$ \\ 1 Faculty of Economics and Development Studies, University of Economics-Hue University, \\ Thua Thien Hue 530000, Vietnam \\ 2 Department of Economics and Rural Development, Gembloux Agro Bio-Tech, University of Liège, \\ 5032 Gembloux, Belgium; philippe.lebailly@uliege.be \\ 3 Faculty of Business Administration, University of Economics-Hue University, \\ Thua Thien Hue 530000, Vietnam; ndhao@hce.edu.vn \\ * Correspondence: ddminh@hce.edu.vn; Tel.: +84-796-727-679
}

Received: 18 October 2020; Accepted: 11 December 2020; Published: 15 December 2020

\begin{abstract}
The key farming communities in Vietnam are generally poor and lack resources to adapt to and mitigate the impacts of climate extreme events (CEEs), but the extent of their adaptation strategies is not well understood. This study aims to analyze the impacts of CEEs, current barriers, and adaptation strategies based on three categories of livelihood strategies. The classification method is first used to divide the livelihood strategy into these three categories, and a multinomial logistic model (MLS) is then applied to determine the set of parameters that affect adaptation options. CEEs result in significant damage in terms of both financial and health dimensions. Various barriers remain, such as the low capacity of relevant staff, lack of local budgets, and outdated methods being used to estimate and mitigate the impacts of CEEs. Notably, there were over $44 \%$, and $28 \%$ conducted reactive and proactive adaptations, respectively, while a high percentage of households did not implement at least one adaptation method, around $27 \%$. The MLS model is able to explain about $51.2 \%$ of the driving factors that influence adaptation strategies. In addition, the behavior of households in choosing adaptation methods shows the difference between perceptions of CEEs' impacts and livelihood strategy profiles. There is a need for a package of adaptive solutions to address the impacts of CEEs that cover the many different household perspectives and involve stakeholders at multiple levels.
\end{abstract}

Keywords: climate extreme events; multinomial logistic regression; livelihood strategy; adaptation

\section{Introduction}

Climate change (CC) and climate extreme events (CEEs), along with their impacts, have attracted great attention from theory to practice. Some recent studies have presented adverse scenarios involving the severe impacts of climate change. Compared to previous articles, the current studies indicate that due to CC issues, many delta regions will be affected earlier and more severely in various parts of the world, such as the Vietnam Delta River, Myanmar, China, and other countries [1-5]. An estimation has shown that 150 to 200 million climate migrants may be affected due to the impacts of environmental issues by 2050 [6,7]. Vietnam, in particular, is among the nine countries where at least 50 million people will be exposed to the impacts of rising sea levels and more powerful storms, among other dangers [6]. Then, in the next couple of decades, Vietnam is also one of the main countries identified as being most vulnerable to climate change in the world [5], although heavier impacts are expected in the long term. In any case, more attention should be paid to developing action plans at the global and national levels. 
In terms of impact evaluation, there are two main schools of thought. The majority of scholars have argued that CC and CEEs leave humans in a significantly vulnerable position [8]. CC and CEEs are likely to affect many dimensions of human life, including the economy, society, and the environment [7,9]. It is difficult to estimate the losses from given issues [8]. The second school of thought states that CC and CEEs can bring some positive benefits elsewhere for the economy. The fact is that we need to consider both views deeply. Reducing the negative issues from CC and CEEs is also part of the Millennium Development Goals (MDGs; specifically MDG7). Importantly, each goal has a specific pattern of interaction with other components of the plan.

Farming communities in Vietnam have been receiving much attention because their livelihood mainly relies on agricultural activities, with a high dependence on weather conditions [6,10]. In addition, the people are generally poor and have a lack of resources to adapt to and mitigate the impact of CEEs, but the extent of their adaptation is not well understood [11]. Therefore, Vietnam is considered to be among the countries most affected by CC and CEEs. There is a growing awareness, from local to international levels, of the imminent need for appropriate adaptation to CC and CEEs [5]. Recently, following new attempts to mitigate and adapt to climate change around the world, Vietnam has entered into collaborations with various organizations and other countries, and many policies and projects have been taking into account the ability to prevent and mitigate the impact of natural disasters and climate change [12-14]. However, the nature and processes of human adaptation to CC and CEEs are still poorly understood and rarely investigated directly [15].

In the theoretical realm, the definitions relating to CEEs along with solutions to adapt to their impacts are hotly debated and at the top of the list of issues to be tackled [16-19]. In proposing methods to minimize the potential adverse impacts, various practitioners proposed the following two steps: (1) determining/recognizing the changes and possible impacts and (2) selecting the best methods to adopt [18]. As a consequence, there is a need to study the adaptation methods from a farmer's point of view, aiming at proposing potentially appropriate solutions to reduce the risks and impacts of given issues. In doing so, various driving factors could be considered to take into account their effects and adaptation methods related to, e.g., the birth rate, educational level, and household perception of the impacts of CEEs [8,20-24]. However, the study has carefully grounded the variables based on the literature review process and current practice at research sites as well as in the context of rural areas in Vietnam. Hence, this study was also a later part of the publication related to the livelihood vulnerability index published in 2019 [18]. The objectives of this study were to (i) identify the impacts of CEEs in the human and financial dimensions; (ii) identify the potential barriers to reducing the impacts of CEEs; (iii) determine household methods of adapting to CEEs and the driving parameters affecting adaptation selection. The study contributes to the literature in two main ways: first, the application of secondary data in a time series to measure the impacts of CEEs; second, the advanced analysis of adaptation strategies based on three categories of livelihood strategies for households. The findings contribute to a significant foundation for policymakers and policy implementers in planning and implementing related policies of CC and CEEs.

The paper includes an introduction; a literature review about the potential impacts of CC and CEEs; this component focuses on the evaluation of the impact of CCEs and how to analyze the factors affecting the adaptation method of the household, and the materials and methods introduce the research site and the application of the multinomial logistic model. Next, the findings and discussions are presented. Lastly, the final section presents our conclusions and recommendations.

\section{Literature Review}

Various studies have posited a strong relationship between CC and CEEs, and the heavy impacts of CEEs are related to the trend in CC [10]. Recently, the prediction of CC and CCEs patterns remain uncertain, and they can vary by place, sector, and community s [24]. CEEs include flooding, storms, typhoons, and saltwater intrusion, all of which have dissimilar effects. According to the fifth Assessment Report of IPCC (2018), which considers the scenario up to 2100, there will be an 
increase by about $50 \%$ in the surface area of 33 delta regions in the world due to flooding, leading to potential adverse impacts on the surrounding areas and the productivity of crop productions will decrease around 10\% [6,25]. Nguyen [26] stated that saltwater intrusion could reach far from the coastline and affect water use activities in estuaries. The above issues are important factors that may contribute to a decrease in wetland areas and increased coastal erosion and salinization of cultivated land and groundwater [27-29]. In the agricultural sector, many scholars proposed some possible estimations of the potential drop in crop yields and production areas in the Mekong and Southeast Asia regions [30-32]. In the Mekong Delta, for example, a loss of 193 thousand hectares of rice paddies may result from inundation and the expected $30 \mathrm{~cm}$ sea level rise by 2050 [32]. Given the impacts of CC and CEEs, some researchers have attempted to convey the multidimensional impacts of CC as well as CEEs, while others have focused only on single-event studies such as flooding or typhoons [33]. As a consequence, evaluation-related issues of CEEs and proposing specific adaptations for each sector are necessary [6].

The impacts of CEEs could potentially be caused by various factors. First, different geographical conditions have different impacts on CEEs, requiring different methods of adaptation [6,10,21,25,34,35]. Additionally, the adaptation plan could also be based on the perceptions of households and their capacity [33]. Some studies have pointed out that different communities suffer differently from the impacts of CEE, even if they live in similar regions. Consequently, some scholars have conducted related studies to identify the divergence of impacts and adaptation strategies between communities [35]. Some scholars have distinguished adaptation strategies based on external and internal factors $[6,10]$. In the same vein, few studies attempted to take into account the goal of identifying the influence of institutional factors on the adaptation capacity of households [6]. The lack of collaboration between the community and related stakeholders could potentially lead to poor efficiency in implementing adaptation strategies [6]. As a result, strengthening the links between the community, related actors, stakeholders, and multiple levels of local government can contribute significantly to reducing the impacts of CEEs [10]. Furthermore, many scholars take into account gender issues, assuming that female-headed households are comparatively more vulnerable because they have less power in decision-making and find it difficult to access related training and updated information [6,21,35-37]. When analyzing the adaptation method from the point of view of households, it is necessary to pay more attention to other factors such as natural resources, represented by land scale; the human capital, represented by education level and birth rate of the household; training course participation; and social capital such as mass organization networks as well as the number of livelihood activities [20]. Scholars believed that different socioeconomic profiles lead to different behavior when selecting adaptation methods [20]. In detail, households with more land are generally involved in agricultural activities; the sensitivity of this sector to weather conditions leads to the expectation that these households will be more active than others in adapting to CEEs. Education level is an important indicator of household success; a higher education level allows households to access knowledge and respond better to CEE-related training [20]. In the same vein, the birth rate of the head of the household could affect the adaptation decisions. On one hand, a higher birth rate means that the head of the households has more local knowledge to adapt to recent CEEs; on the other hand, there may be less motivation for income generation and it could be easier to ignore the impacts of CEEs. Being a member of at least one mass organization could bring a household more opportunities for learning, sharing, and discussing not only the impacts of CEEs but also various socioeconomic phenomena [20]. A mass organization plays the role of connector between a community and local government in enhancing the collaboration to reduce the impacts of CEEs. It is similar in the case of training participation; this action allows households to raise their capacity to adapt to the impacts of CEEs as well as voicing their concerns in a workshop or conference setting. Under the assumption that a household aims to reduce potential risks as well as increase income, this indicator permits us to predict which households will be more active in adapting to the impacts of CEEs than others. Last but not least, some scholars have attempted to take into account the relationships between some explanatory variables such as 
migration [7], farm expansion possibilities, distance from the household to the market/healthcare capital, or early warning systems and the adaptation choices [20].

Evaluating the impacts of CEEs could be based on some different approaches. Information related to climate could be accessed from general statistical offices and could build on the livelihood vulnerability index (LVI). Moreover, stories about losses in the financial and human dimensions give a sense of the change in CEEs as well as their impacts in different sectors, which could be applied to understanding vulnerability from the householder's point of view. Furthermore, using secondary data provided by the Department of Natural Disaster Prevention and Control is an optional but important input for evaluating the process [24]. Recently, tackling the impacts of CEEs generally involves evaluating the LVI to measure the level of household vulnerability and the adaptation strategy selection [18]. This is the foundation to propose sustainable solutions for reducing the impacts of CEEs. The LVI was proposed and developed by Hahn in 2009 [37] and has been continuously adapted and widely applied in various fields. The LVI ranges from 0 to 1 , with the value of 1 , meaning that the community is more vulnerable. The methods of adapting to the impacts of CEEs can be classified into different approaches [20]. Some studies proposed a binary model with two steps. First, a household is asked about perceptions regarding the impact of CEEs; then, the information of households that agreed on changes can be used to analyze the adaptation options. Some practitioners worked in advance on the identification of the main barriers of households, then identified adapting and mitigating options. Then, the multinominal linear logistic model with more than two options was applied to determine the factors affecting the choices of the household. To identify the divergence of models, one can use the referent/base category and then rely on the significance level of the statistic Test to conclude, which is the better model [38]. The number of adaptation methods depends on the practical implementation of households. Scholars use the raw data to set the model, with the dependent variable operating as the discrete choice category. The answers could also be grouped into larger groups of methods, including three options: no adaptation method, reactive/short-term method, and proactive/long-term method. This study was therefore designed to group the adaptation methods of households into three blocks: (i) no adaptation, (ii) reactive adaptation, and (iii) proactive adaptation. A post comparison analysis to select the best model was implemented on a case-by-case basis, comparing (i) and (ii), (i) and (iii), and (ii) and (iii). As stated in the introduction, this study took into account the relationships between livelihood strategies and adaptation methods under the belief that different livelihood strategy profiles will affect the behavior of households when in choosing adaptation methods. Based on the contribution of each component to the total income, the livelihood strategies were grouped into three categories: (i) agri-based strategy, (ii) mixed-based strategy, and (iii) exit-based strategy. A distribution of each component of larger than $50 \%$ identified the specific strategy according to the three proposed options.

\section{Materials and Methods}

\subsection{Research Site Selection}

The baseline study was completed by the author Nguyen Dang Hao in 2009 [39]. In this study, four districts of the coastal sandy zone were selected, namely Quang Dien, Phong Dien, Phu Vang, and Phu Loc (see Figure 1). The coastal sandy zone constitutes over $18 \%$ of the total provincial area and contains approximately $50 \%$ of the total population of the province. The average population per district varies considerably and ranges from 92,000 inhabitants in Quang Dien to 179,000 inhabitants in Phu Vang. The majority of the population of the region lives in rural areas [40].

In this region, there were various adverse climate events such as early flooding and storms, temperature increases in the summer, and rainfall reduction in the winter. We must also take into account the poor, sandy soil resulting from the lack of water supply and the risk of salinity intrusion, as well as the high frequency of extreme drought. Households are still lacking in terms of their ability to adapt to changes, coupled with a lack of collaboration between local communities and multiple levels of local government; this highlights the need to research farming adaptations. This area borders the sea 
and has a total length of $105 \mathrm{~km}$, crossing the Tam Giang-Cau Hai Lagoon (one of the biggest lagoons in Southeast Asia), which contains a variety of species and natural resources and has significantly contributed to Thua Thien Hue's GDP as well as the livelihood of households.

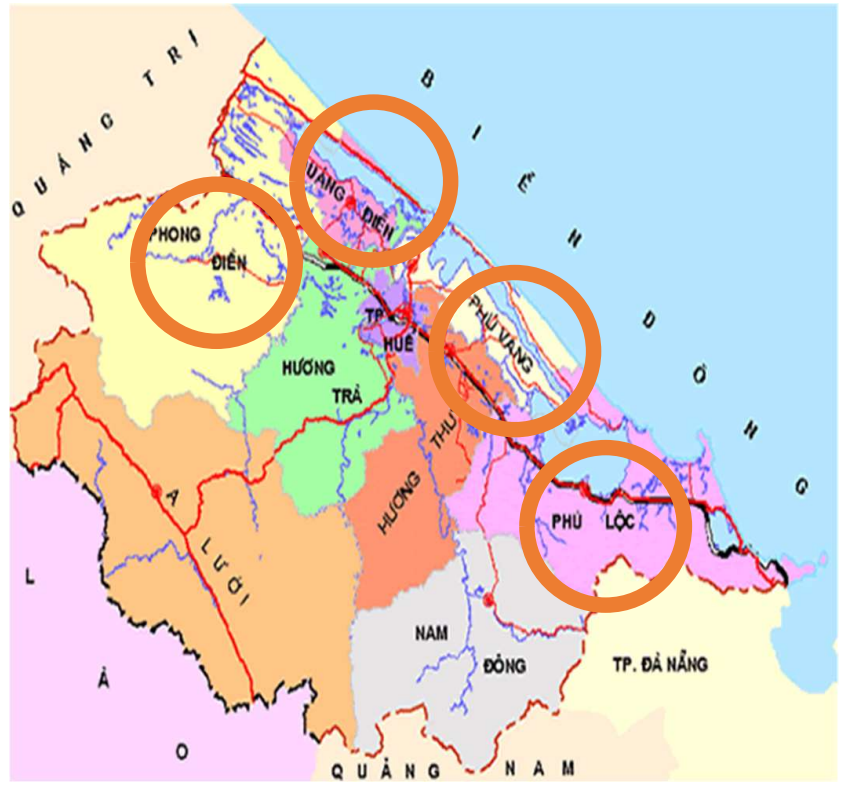

Figure 1. Thua Thien Hue Province and research areas [40].

\subsection{Data Collection}

For this study, secondary and primary data were used in the analysis. The secondary data included relevant literature reviews to construct the framework as well as the base indicators. In addition, climate data were collected from many sources to serve the needs of the study.

We employed various data collection methods to obtain optimal results (Figure 2). The historical profile of the village was used to identify the main CEEs. Key informant interviews (KII), two at the provincial level, seven at the district level, and seven at the commune level, were organized to capture general information about the livelihood strategy, livelihood activity, sociodemographic conditions, and context of vulnerability at the research site. In-depth interviews contributed to a picture of related issues to identify potential CEE adaptations. A focus group discussion was carried out to brainstorm about current conditions of livelihood strategy, achievements, and adaptation to CEEs.

As mentioned above, this study applied the sample size method to the baseline data in 2009 [39] in four districts, representing the coastal sandy zone in TTH. In the baseline study, conversations were organized with key informants at multiple levels to identify the study site. Likewise, relevant documents such as maps and annual reports were selected. Some key criteria had to be strictly observed to ensure that study sites met the requirements: being representative of the rural context and the diverse agroecological and socioeconomic conditions, consisting of multiple levels of infrastructure access, and the inclusion of a range of livelihood activities. For the targeted households, a two-stage design method was applied. In detail, this meant that at the district and commune level, four districts with seven communes were chosen based on the representativeness of agroecological conditions and access to infrastructure. At the village level, we chose seven villages representative of the agroecological conditions and livelihood activities in the area. At the household level, we chose 136 households representative of the agroecological conditions and livelihood activities in the village. After 10 years, only 110 households remained for numerous reasons: 26 were removed from the study due to various reasons, 6 households migrated to other provinces, 12 heads of the household died, 2 heads of household had a high birth rate, so they did not have the ability to answer the survey, and 6 households were not willing to complete the survey. 


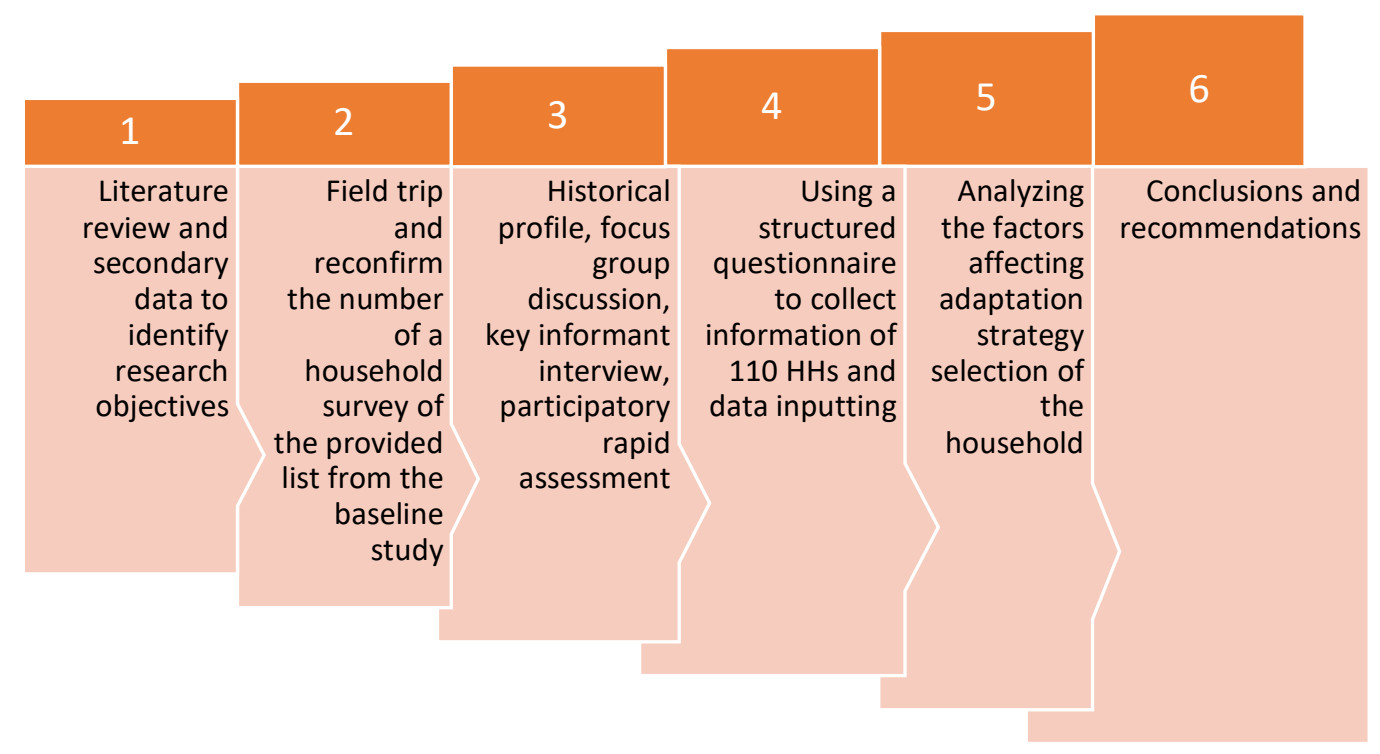

Figure 2. Research design framework.

\subsection{Methods}

This study applied the optimal utility theory to assess the decision-making of households on whether or not to implement a method to adapt to the impact of CEEs. The core assumption of this model is that households will select an adaptation method based on the belief that they could perceive the utility of their decision compared to another choice. A farmer $n$ chooses from a set of mutually exclusive adaptation strategies, $\mathrm{j}=1 \ldots$, J. The decision-maker obtains a certain level of utility, Unj, from each alternative. With the assumption that $U_{j}$ and $U_{k}$ represent the utility of two selections, the linear random utility model is as below:

$$
\mathrm{U}_{\mathrm{j}}=\beta_{\mathrm{j}}^{\prime} X_{\mathrm{j}}+\varepsilon_{\mathrm{j}} \text { and } \mathrm{U}_{\mathrm{k}}=\beta_{\mathrm{j}}^{\prime} \mathrm{X}_{\mathrm{k}}+\varepsilon_{\mathrm{k}}
$$

Here, $U_{j}$ and $U_{k}$ are the levels of utility when households implemented the adaptation strategy following $j$ and $k ; X_{j}$ stands for socioeconomic variables affecting the decisions of the households; $\beta_{\mathrm{j}}$ and $\beta_{\mathrm{k}}$ are the estimators, and $\varepsilon_{\mathrm{j}}$ and $\varepsilon_{\mathrm{k}}$ are the random standard errors. A household had a decision to implement strategy $\mathrm{j}$ when the utility level from the selected strategy was larger than the rest (k as an example). This could be presented as follows:

$$
\mathrm{U}_{\mathrm{ij}}\left(\beta_{\mathrm{j}}^{\prime} \mathrm{X}_{\mathrm{i}}+\varepsilon_{\mathrm{j}}\right)>\mathrm{U}_{\mathrm{ik}}\left(\beta_{\mathrm{k}}^{\prime} \mathrm{X}_{\mathrm{i}}+\varepsilon_{\mathrm{k}}\right), \mathrm{j} \neq \mathrm{k}
$$

Then, MLR is applied to analyze the factors affecting the method of adaptation to climate extreme events. The MLR model, a discrete choice model in climate change adaptation research, is based on the theory of adaptation decision [41]. This method was previously used by Bryan and Kandulu (2009), Tazeze, Haji and Ketema (2012), Obayelu, Adepoju and Idowu (2014) [41-43]. Following this model among the set of adaptation options, the probability that a farmer (i) will choose an adaptation alternative (j) from the options could be defined as follows:

$$
\operatorname{Prob}\left(\mathrm{Y}=\frac{\mathrm{j}}{\mathrm{X}}\right)=\mathrm{P}\left(\mathrm{U}_{\mathrm{ij}}>\frac{\mathrm{U}_{\mathrm{ik}}}{\mathrm{X}}\right)
$$

where ' $X$ ' is a vector of explanatory variables, $U_{i j}$ and $U_{i k}$ are the perceived utilities for the farmer (i) of adaptation $(\mathrm{j})$ and $(\mathrm{k})$. The response probabilities of the multinomial logit model are

$$
Y_{j}=\frac{\partial P j}{\partial X i}=\beta_{0}+\beta_{1} X_{1}+\beta_{2} X_{2}+\beta_{3}+\text { ei }
$$


In this study, the list of adaptations, as presented previously, will be split into three categories. (1) $\mathrm{Y}=0$ : households do not implement any adaptation strategy; (2) $\mathrm{Y}=1$ : households implement a reactive adaptation; (3) $\mathrm{Y}=2$ : households implement a proactive adaptation. The selection of a reactive adaptation is generally related to CEEs in the short term: before, during, and after their occurrence. These seem to be less efficient solutions compared to protecting housing, facilities, or humans. Some other possibilities include moving facilities, animals, or humans to safe places, using more fertilizer/manure for crops, or placing sandbags on the roof. Proactive adaptations are long-term strategies and seem to be more efficient. Possible solutions could be taken into consideration, such as changing calendar patterns, applying new varieties, upgrading a house's roof, and building a second floor.

Exploratory variables $\left(X_{j}\right)$ are set into the model, including age, education, gender, family size, land scale, number of livelihood activities, participation in a training course, membership of an organization, perceptions, and livelihood strategies (Table 1). We classified the livelihood strategies into three categories of agri-based, mixed-based, and exit-based. We used the amount of income contributed to the total to identify the specific type of livelihood strategy. Contributing income sources were major activities that include crops, animals, aquaculture, forestry, wages, none farm and remittances. A household will be grouped in the agri-based category on the condition that the contribution of crops, animals, aquaculture, and forestry accounts for more than $50 \%$ of the total income. Similarly, a household will be identified as exit-based when off-farm earnings (wages and/or remittances) account for more than $50 \%$ of the total income. The remaining households were considered mixed-based.

Table 1. Explanation of variables in multinomial logistic regression.

\begin{tabular}{lcc}
\hline \multicolumn{1}{c}{ Variable } & Description & Theoretical Expectation Sign \\
\hline \multicolumn{1}{c}{ Y } & $\begin{array}{c}\text { 0: No Adaptation; 1: Reactive } \\
\text { Adaptation; 2: Proactive } \\
\text { Adaptation }\end{array}$ & \\
\hline X1 (Age of the head of HH) & Year & $+/-$ \\
X2 (Education of the head of HH) & Year & + \\
X3 (Female head of HH) & 1: male; 0: female & + \\
X4 (Family size) & Person & +- \\
X5 (Land area) & Sao (1 sao = 500 $\left.\mathrm{m}^{2}\right)$ & + \\
X6 (No. of livelihood activities) & Activity & + \\
X7 (Participation in a training course) & 1: yes; 0: no & + \\
X8 (Membership of at least one & 1: yes; 0: no & + \\
organization) & 1: impact; 0: no & + \\
X9 (Perception) & 0: agri-based; $1:$ mixed-based; & $+/-$ \\
X10 (Livelihood strategy) & 2: exit-based & + \\
\hline
\end{tabular}

\section{Results and Discussion}

\subsection{Trends and Impacts of Climate Extreme Events}

CEEs follow unpredictable trends. Statistics on CEEs (flooding, drought, typhoons, precipitation, and variability of temperature) showed a dramatic fluctuation leading to difficulties in various activities, mostly in the agricultural sector. Unpredictable trends lead to huge problems with estimating and mitigating the impacts of CEEs. Changes occurred not only in the frequency of events but also in terms of the start and end times (Table 2). Prior to 2008, CEEs generally followed a predictable pattern, which made it easier for the community and related stakeholders to cope with CEEs. However, CEEs have recently not followed any rules compared to the past, leading to an increase in potential risks and the vulnerability of the community. In terms of flooding, the number of flooding events has decreased since 2008. Remarkably, the flooding has started earlier in the year, leading to changes in the crop calendar, especially in the case of rice cultivation. A lack of flooding could reduce the fertility of land because 
of the reduction in alluvial soils. Moreover, the livelihood of the community based on aquaculture activity was also negatively affected. Typhoon events have tended to increase since 2008 and fluctuated dramatically on the East Sea and within this province. Tropical depressions were underestimated in both the East Sea and this province. There was a decrease in cyclones during 2008-2014 compared with before 2008, but a significant increase was observed from 2015 to 2017, while there were none in 2018. The frequency of extreme cold events has been quite a stable year to year, but their timing and intensity have changed significantly. CEEs now have complicated trends, which will be a huge challenge for the community and related actors in attempts to mitigate and adapt to CC.

Table 2. Statistics of the number of events for the indicated climate extreme events (CEE) from 1999 to 2018 .

\begin{tabular}{|c|c|c|c|c|c|c|c|c|}
\hline \multirow{2}{*}{ No. } & \multirow{2}{*}{$\begin{array}{l}\text { Type of CEE } \\
\text { Year }\end{array}$} & \multirow{2}{*}{ Flooding } & \multicolumn{2}{|c|}{ Typhoon } & \multicolumn{2}{|c|}{ Tropical Depression } & \multirow{2}{*}{ Cyclones } & \multirow{2}{*}{$\begin{array}{c}\text { Extreme } \\
\text { Cold Events }\end{array}$} \\
\hline & & & On the East Sea & Direct Impact & On the East Sea & Direct Impact & & \\
\hline 1 & 1999 & 7 & * & 2 & * & 1 & 1 & * \\
\hline 3 & 2001 & 4 & * & 2 & 0 & 0 & 0 & 26 \\
\hline 4 & 2002 & 5 & 5 & 0 & 6 & 0 & 2 & 28 \\
\hline 5 & 2003 & 1 & 7 & 1 & 5 & 0 & 4 & 26 \\
\hline 6 & 2004 & 2 & 5 & 2 & 2 & 1 & 0 & 25 \\
\hline 9 & 2007 & 6 & 7 & 2 & 3 & 0 & 4 & 22 \\
\hline 10 & 2008 & 5 & 10 & 2 & 6 & 1 & 2 & 22 \\
\hline 11 & 2009 & 7 & 11 & 1 & 3 & 2 & 0 & $*$ \\
\hline 12 & 2010 & 4 & 6 & 1 & 5 & 2 & 0 & 21 \\
\hline 13 & 2011 & 4 & 7 & 2 & 7 & 0 & 0 & 13 \\
\hline 14 & 2012 & 3 & 9 & 2 & 2 & 0 & 0 & 24 \\
\hline 19 & 2017 & 2 & 16 & 5 & 4 & 1 & 4 & 24 \\
\hline 20 & 2018 & 0 & 9 & 5 & 9 & 0 & 0 & 28 \\
\hline
\end{tabular}

(Source: Department of Natural Disaster Prevention and Control in Thua Thien Hue.) * Unidentified information.

Thua Thien Hue is one of the key provinces of Vietnam facing heavy impacts from CC and CEEs each year. Local governments have made numerous attempts to collaborate with multiple stakeholders and local communities to reduce the impacts from CC and CEEs, which has contributed to raising the adaptive capacity as well as minimizing the impacts of CEEs. However, as it is located in the most flood-prone region of Vietnam, this province experiences heavy annual impacts in various areas, including housing facilities, related facilities in the educational sector, the agricultural and forestry sector, irrigation systems, infrastructure, industry, water security, and environmental control. The losses in each sector varied from year to year and depended on the specific CEE and how strong the collaboration was between related actors and communities.

The information presented in Figure 3 shows the impact of CEEs in three dimensions, including the number of deaths and injuries along with the total economic losses. The number of deaths caused by CEEs fluctuated gradually year by year. The historic flooding in 1999 is a painful memory, with 359 deaths and 305 injured. However, since this time, injuries and deaths due to CEEs (mainly flooding) have decreased dramatically. This was a result of the various attempts to reduce the enormous impacts from CEEs, coupled with the change in frequency and intensity of the floods and typhoons that occurred in this province. In terms of financial aspects, CEEs are a heavy drain on the local economy each year, with enormous financial losses in various sectors. The financial losses reached a peak of 2931 million VND in 2006, leading to serious problems in many dimensions. In terms of the years following 2006, losses fluctuated considerably depending on the frequency and intensity of CEEs. In particular, the establishment of infrastructure, including dams, small-scale hydropower plants, and dikes supported by the government budget and international projects, significantly contributed to reducing the financial losses for the province. CC and CEEs are the leading factors placing local citizens into vulnerable contexts, especially agri-based farmers. 


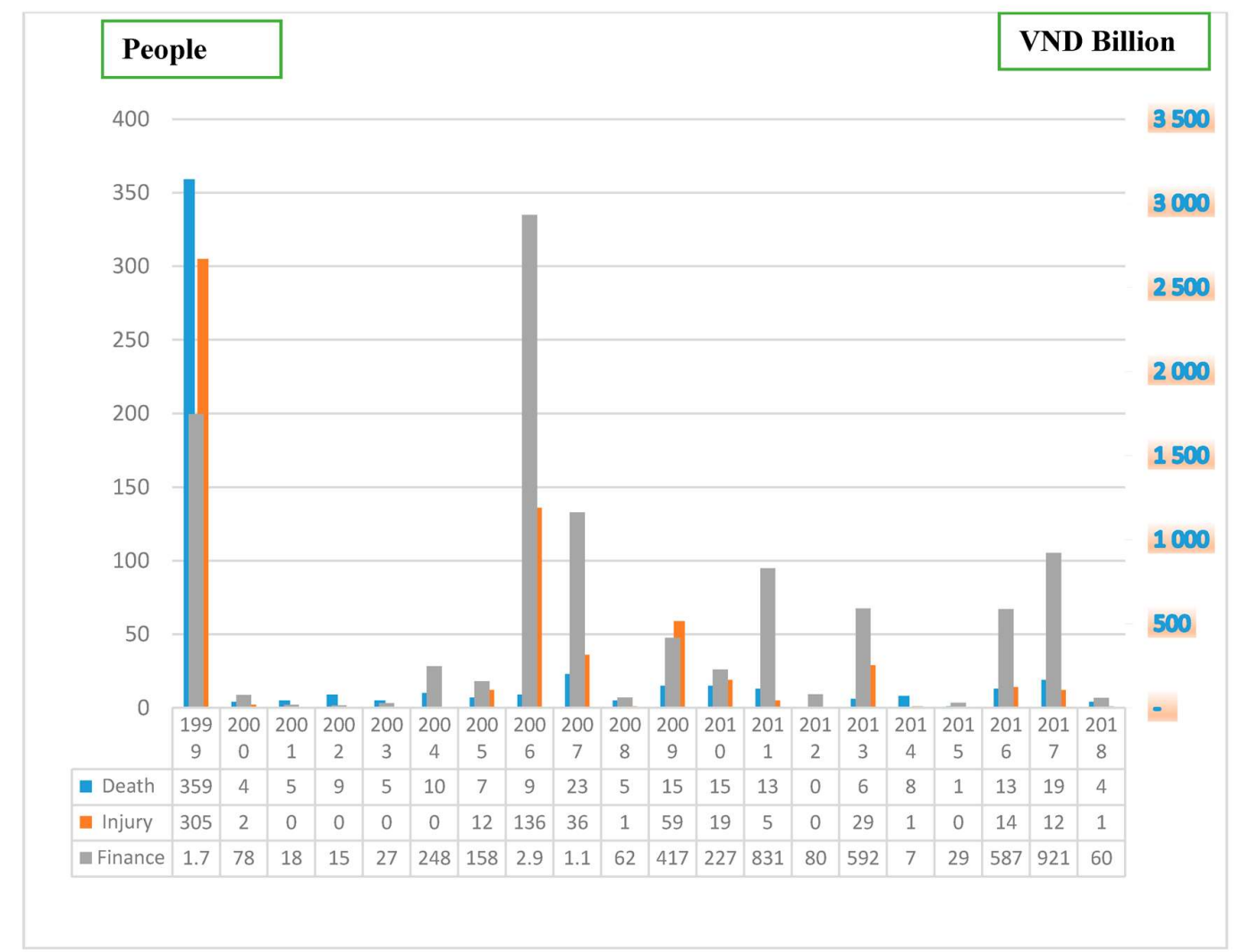

Figure 3. Impacts of CEEs on humans from 1999 to 2018. (Source: Department of Natural Disaster Prevention and Control in Thua Thien Hue).

\subsection{Identification of Barriers/Limitations in Mitigating and Adapting to the Impacts of CEEs}

CEEs are a complicated matter leading to many difficulties. In mitigating and adapting to the impacts of CEEs, we need to follow-updated critical innovation standards. However, there is a lack of collaboration between multiple stakeholders and a shortage of adaptive capacity at different levels of local government, leading to a reduction in efficiency. Moreover, officers have worked not only adapting and mitigating sectors but also handled other official duties leading to low-efficiency work-loading. A lack of modern facilities and tools at the district and commune levels causes a mismatch in terms of the requirements for mitigating and adapting to the impacts of CEEs, especially emergency events. In addition, a lack of planning and necessary information means officers in this sector do not currently meet the eligibility requirements for finding solutions. Technology can allow for the estimation of weather conditions, which will help with the mitigation of and adaptation to the impacts of CEEs. However, poorly supported infrastructure and the lack of an automatic rain gauge system, oceanographic monitoring stations, and innovative estimating techniques lead to more difficulties. Shortages of permanent facilities, vehicles and road systems lead households to be passive about adapting to CEEs. While training courses for raising the awareness and adaptive capacity of the community have been taken into consideration, low-efficiency and motivation continue to be problems. Last but not least, the local budget for preventing and overcoming CEE-related issues remains limited.

\subsection{Brief Information about Driving Factors}

Research findings from the 110 surveyed households indicated that the average age of household members was quite high (Table 3). This study surveyed the same households as the baseline study in 2009 , and the average age of the head of the households was over 61 , or a little older in the case of households in the agri-based model at approximately 62.5. As a consequence, livelihood activities and adaptation selection were strongly influenced by older people's lower participation in farming and 
nonfarming activities. The educational level of the head of the household was quite similar between the three models, with an average score of 6.6 schooling years; households of the exit-based model had the highest level with 7.3 schooling years. These results reflect the general educational status of the last generation of households at the study sites. The majority of households were male-led (an average of 95\%); in some cases, the head of the household worked far away from the hometown-if this continued for longer than six months, then a female could be considered to play the role of the household head. There was not much difference in this criterion between the three livelihood strategies. Findings again indicated little difference among the three groups in terms of the family size, with the average being 4.4 members. This could be interpreted as a successful attempt to reduce the average population growth rate in a strategy aimed at removing pressure for rural economic development. The land scale was also an important factor used to analyze the farming strategy and adaptation to CEEs. This phenomenon is related to the income contribution of each major component, as previously discussed. On average, households had a land area of 22.5 sao (around $1.1 \mathrm{ha}$ ); the highest level, at 24.1 sao, was for agri-based households. This is lower than for households in the Red and Mekong River Delta. Households in rural areas generally diversify their livelihood to reduce potential risks. There was a similarity in the number of livelihood activities, approximately 3.4 on average. The percentage of households joining in the training course contributed significantly to raising the capacity of the households to reduce the impacts of CEEs. Around $66 \%$ of households attended training courses, most of them in the mixed-based model (77\%), followed by households in the exit-based model $(64 \%)$, with the lowest percentage attending those of the agri-based model (61\%).

Table 3. Information about driving variables.

\begin{tabular}{|c|c|c|c|c|c|}
\hline Variable & Measurement & Agri-Based & Mixed-Based & Exit-Based & Average/Total \\
\hline X1 (Age of the head of $\mathrm{HH}$ ) & Year & 62.5 & 61.3 & 61.1 & 61.9 \\
\hline X2 (Education of the head of $\mathrm{HH}$ ) & Year & 6.4 & 6.7 & 7.3 & 6.6 \\
\hline X3 (Female head of $\mathrm{HH}$ ) & $\%$ & 95 & 97 & 93 & 95 \\
\hline X4 (Family size) & Person & 4.4 & 4.6 & 4.3 & 4.4 \\
\hline X5 (Land area) & Sao $\left(1 \mathrm{sao}=500 \mathrm{~m}^{2}\right)$ & 24.1 & 21.8 & 17.7 & 22.5 \\
\hline X6 (No. of livelihood activities) * & Activity & 3.3 & 3.4 & 3.6 & 3.4 \\
\hline X7 (Participation in a training course) & $\%$ & 61 & 77 & 64 & 66 \\
\hline $\begin{array}{l}\text { X8 (Membership of at least one } \\
\text { organization) }\end{array}$ & $\%$ & 100 & 97 & 86 & 97 \\
\hline X9 (Perception) & $\%$ & 80 & 69 & 64 & 75 \\
\hline X10 (Livelihood strategy) & $\%$ & 27.3 & 44.5 & 28.2 & 100 \\
\hline
\end{tabular}

Source: households surveyed in 2017-2018. ${ }^{*}$ Number of livelihood activities based on the join of household in the major sector (A major of livelihood activity of crop activity as an example could include more than two kinds of crop action).

In rural areas, various social organizations were established to support households. Organizations also play roles in connecting households with multiple stakeholders, including multiple levels of local governments. The study found that the majority of households, an average of $97 \%$, were involved in at least one organization. The perception of households in terms of recognizing the impacts of CEEs was taken into consideration; $75 \%$ of households agreed that they experienced losses due to CEEs. The highest percentage was in the case of the agri-based model $(80 \%)$, followed by the mixed-based model $(69 \%)$ and the exit-based model $(64 \%)$. A recall story was used to measure the impacts of CEEs on livestock as well as housing facilities over the last three years.

\subsection{Description of Adaptation Methods and Livelihood Strategies}

Table 4 provides the findings from the surveyed households on adaptation methods based on the livelihood strategy. Around $75 \%$ of households perceived that they had been affected by CEEs. Over $27 \%$ of households did not have any adaptation method to adapt to the impacts of CEEs. Of these, over $43 \%$ of the households were in the exit-based model, with 30\% each in the agri-based and the rest belongs to exit-based models with approximately $27 \%$. There were very interesting findings in that approximately $45 \%$ of households tended to implement reactive adaptation methods. The majority 
of households in the agri-based model selected this adaptation method, representing approximately $26 \%$ in total and over $57 \%$ of those that adopted reactive adaptation methods, while approximately $12 \%$ of households in total were in the mixed-based model representing $26.5 \%$ of those engaged in reactive adaptation methods. Returning to the exit-based model, just a few households selected reactive adaptation representing $7 \%$ in total and around $16 \%$ of those in this section. In terms of proactive adaptation, the findings indicated that just over $28 \%$ of households chose this method, implying that households were more familiar with implementing short-term strategies-this is not a sustainable vision. Households in the exit-based and mixed-based models favored implementing proactive methods, with roundly $16 \%$ and over $8 \%$ in total or approximately $55 \%$ and $29 \%$ of this method, respectively. A small percentage of households in the agri-based model selected proactive adaptation, perhaps due to the demographics of the households (older household head and lower education compared to households with another livelihood strategy).

Table 4. Adaptation method and livelihood strategy.

\begin{tabular}{ccccc}
\hline $\begin{array}{c}\text { Adaptation } \\
\text { Method }\end{array}$ & $\begin{array}{c}\text { Livelihood } \\
\text { Strategy }\end{array}$ & $\begin{array}{c}\text { No. of Members } \\
\text { in HH }\end{array}$ & $\begin{array}{c}\text { \% of HH in } \\
\text { Total }\end{array}$ & $\begin{array}{c}\text { \% of HH in the } \\
\text { Adaptation Method }\end{array}$ \\
\hline No. of adaptations & $\begin{array}{c}\text { Agri-based } \\
\text { Mixed based } \\
\text { Exit-based }\end{array}$ & 9 & 8.2 & 30.0 \\
Subtotal & 13 & 7.3 & 26.7 \\
Reactive & Agri-based & 28 & 11.8 & 43.3 \\
adaptations & Mixed-based & 13 & 27.3 & 100 \\
& Exit-based & 8 & 25.5 & 57.1 \\
Subtotal & & 49 & 11.8 & 26.5 \\
Proactive & Agri-based & 5 & 7.3 & 16.3 \\
adaptations & Mixed-based & 9 & 4.5 & 100 \\
\hline Subtotal & Exit-based & 17 & 8.2 & 16.1 \\
\hline Total & & 31 & 15.5 & 29.0 \\
& & 110 & 28.2 & 54.8 \\
\hline
\end{tabular}

Source: households surveyed in 2017-2018.

\subsection{Prediction of the Adaptation Methods of Households}

Information on the MLS model is presented in Table 5, with an estimation of the appropriate model and indications of how driving factors influenced households' choice of adaptation methods. Turning to the results of the estimated model, the values of pseudo- $R^{2}$ and log-likelihood were 0.516 and 155.918 , respectively, which indicates that the dependent variables could explain $51.6 \%$ when selecting the adaptation method of households under the assumption that other factors are fixed. The given score was good for this kind of model, implying that results from this study fit the scientific requirements to explain the study's targets. In other words, the rest of the factors contributed to explaining $48.4 \%$ of the decision-making of households. Additional factors could be taken into consideration, such as the geographical conditions, policy support, or infrastructure system improvement.

Related to the application of the discrete choice model, the selection of different reference categories to make comparison do not change the meaning of the findings. In this study, we proposed applying three kinds of models for the three kinds of adaptation methods. In the case of the no adaptation model, the reference category was the reactive adaptation model. In the same vein, the reactive adaptation model applied the category of proactive adaptation while the proactive adaptation was based on the reference option of no adaptation. 
Table 5. Parameter estimates of the multinomial logistic regression model for the three adaptation methods.

\begin{tabular}{|c|c|c|c|c|c|c|}
\hline \multirow{3}{*}{$\begin{array}{c}\text { Model } \\
\text { Variable }\end{array}$} & \multirow{2}{*}{\multicolumn{2}{|c|}{$\frac{\text { Y0-Y1 }^{1}}{\text { (No Adaptation) }}$}} & \multirow{2}{*}{\multicolumn{2}{|c|}{$\begin{array}{c}\mathrm{Y}-\mathrm{Y}^{2}{ }^{2} \\
\text { (Reactive Adaptation) }\end{array}$}} & \multirow{2}{*}{\multicolumn{2}{|c|}{$\begin{array}{c}\mathrm{Y} 2-\mathrm{Y}^{3} \\
\text { Proactive Adaptation }\end{array}$}} \\
\hline & & & & & & \\
\hline & $\beta$ & Sig. & B & Sig. & $\beta$ & Sig. \\
\hline Intercept & 7.461 & 0.186 & -20.246 & 0.000 & 12.785 & 0.032 \\
\hline X1 (age of the head of $\mathrm{HH}$ ) & 0.199 & 0.001 & 0.016 & 0.752 & -0.215 & 0.001 \\
\hline $\mathrm{X} 2$ (education of the head of $\mathrm{HH}$ ) & -0.124 & 0.242 & 0.132 & 0.135 & -0.009 & 0.937 \\
\hline X3 (female head of $\mathrm{HH}$ ) & -16.172 & 0.000 & 17.400 & & -1.229 & 0.442 \\
\hline X4 (family size) & 0.042 & 0.881 & 0.149 & 0.497 & -0.190 & 0.511 \\
\hline X5 (land area) & 0.012 & 0.389 & 0.003 & 0.815 & -0.015 & 0.373 \\
\hline X6 (no. of livelihood activities) & -0.705 & 0.087 & -0.125 & 0.658 & 0.831 & 0.061 \\
\hline X7 (participation in training course) & 1.065 & 0.177 & -0.723 & 0.243 & -0.342 & 0.673 \\
\hline X8 (membership of at least one organization) & -0.812 & 0.659 & 0.832 & 0.622 & -0.020 & 0.991 \\
\hline X9 (perception) & -1.715 & 0.027 & -0.432 & 0.608 & 2.147 & 0.013 \\
\hline X10 (livelihood strategy) & & & & & & \\
\hline$($ agri-based $=1.00)$ & -1.608 & 0.058 & 2.695 & 0.001 & -1.086 & 0.238 \\
\hline$($ mixed-based $=2.00)$ & -0.061 & 0.945 & 1.278 & 0.061 & -1.217 & 0.159 \\
\hline (exit-based = 3.00) & $0^{\mathrm{a}}$ & & $0^{\mathrm{a}}$ & & $0^{\mathrm{a}}$ & \\
\hline Pseudo- $R^{2}$ & 0.516 & & & & & \\
\hline Log-likelihood fn. & 155.918 & & & & & \\
\hline No. of observations & 110 & & & & & \\
\hline
\end{tabular}

A total of 10 dependence variables are set into the model, and the livelihood strategy domain was classified into three options. Findings from the MLS model reported that there were five dependent variables, i.e., X2 (education of the head of $\mathrm{HH}$ ), X4 (family size), X5 (land area), X7 (participation in the training course), and X8 (Membership of at least one organization), that did not affect the selection of adaptation strategy of the household. The education level of the household may not reflect differences between households. Adaptation selection was possibly influenced by other similar theoretical domains like the experience of adapting to CEEs in the past or the indigenous knowledge of local people. In terms of family size, as mentioned before, due to various efforts from multiple levels of local government and awareness-raising among citizens about reducing the population growth rate, the family size fluctuated around $4-5$ members per family, with little variation. This could be a reasonable explanation for the given findings. The land area of households was significantly related to income from the agricultural base, but, in this analysis, it was not related to the adaptation method, although the sign of the coefficient supported the idea that households owning more land will select the agri-based and mixed-based strategies. As for the training course, households have recently received much attention in terms of technology and market support, but it may be that the majority of households have a similar experience of training courses about reducing the impacts of CEEs. In the same vein, households have many chances to participate in at least one organization; in doing so, the household receives related information on climate adaptation training events.

X1 (age of the head of $\mathrm{HH}$ ) had a significant statistical effect in the no adaptation and proactive adaptation models. Households with a high birth rate are more likely to make no attempt to adapt to the impacts of CEEs. Both models indicated that when the age of the household head increases by one year, the possibility of changing from a reactive adaptation to no adaptation increases 0.199 -fold, and the possibility of changing from a proactive adaptation to no adaptation increases 0.215 -fold. This implies that to raise awareness about applying adaptation methods in households, it is necessary to focus on other family members [20].

X3 (female head of $\mathrm{HH}$ ) was a very interesting finding in that a female head of household tended to select a reactive adaptation method in response to the impacts of CEEs. The value of the coefficient of the X3 variable was -16.172 , which indicates that a household with a female head has an increased possibility of selecting a reactive adaptation of over 16 times. This finding indicated a positive trend resulting from women's right to be involved in household decision-making. Another 
explanation for the given finding is that they had to adapt to their vulnerable position because the lack of males in their household may put them in more dangerous situations when CEEs occur. However, the percentage of female heads of households was quite small (only $5 \%$ ), leading to less statistically significant explanations. Therefore, it is necessary to take up an alternative approach, such as an FGD, key informant interview, or increased sample size, to ensure more statistically robust results.

X6 (number of livelihood activities): the findings were statistically significant in two models (no adaptation and proactive), with some interesting observations. The value of the coefficient of $\mathrm{X} 6$ in the no adaptation model was -0.705 , i.e., when households joined one more livelihood activity, the possibility of selecting no adaptation method decreased 0.705 -fold. On the other hand, the households did not tend to implement reactive adaptation methods. By contrast, households tended to implement a proactive adaptation method. Households increased the possibility of making a proactive adaptation up to 0.831 -fold when adding one more livelihood activity. The result of the proactive model showed better results than the no adaptation model, implying that by joining more livelihood activities, households will be more motivated to apply the proactive adaptation method.

X9 (perception): households that perceived that CEEs lead to negative impacts for themselves implemented adaptation methods to cope with given issues. Information from the study revealed that both models, no adaptation and reactive adaptation, had statistical significance. Regarding the no adaptation model, households reported that they experienced losses due to climate issues, and the possibility of no adaptation decreased 1.608-fold, while in the case of a proactive adaptation, households reported that damage caused by climate issues could increase the possibility of selecting this method up to 2.147-fold (compared to the no adaptation model). Moreover, the significance level confirmed that the proactive model could better explain the results than the no adaptation model. These findings spur us to focus on developing advice to raise the awareness of households so they can recognize the impacts of CEEs.

X10 (livelihood strategy): the exit-based model played the role of the reference category. The research findings indicated the statistical significance of both models, no adaptation and reactive adaptation, in terms of being agri-based, whereas, in terms of being mixed-based, only the reactive adaptation model was statistically significant. In particular, a household with an agri-based strategy had a 1.068-fold decreased possibility of having the no adaptation method; in other words, households were 1.068-fold more likely to apply reactive adaptation. In the case of a reactive adaptation, households increased the possibility of 2.695 -fold to apply reactive adaptation than proactive adaptation. The second model showed a better explanation than the first model, but, on the whole, households in the agri-based model generally applied reactive adaptation to cope with the current impacts from CEEs. This could be due to the characteristics of households being based on agricultural activities. It will be important for local governments to engage in policy intervention in terms of finding long-term solutions. Turning to the mixed-based strategy, the findings also indicated that reactive adaptation was a common way to cope with CEEs: the household was 1.278 -fold more likely to apply reactive adaptation than proactive adaptation.

\section{Conclusions}

CC and CEEs and their impacts have been drawing much attention, from theory to practice. Vietnam in general, and the delta region in Thua Thien Hue province specifically, have been heavily impacted by CEEs. The majority of households living in rural areas are involved in agricultural activities, which leaves them in a more vulnerable position. A study was performed in the coastal sandy zone with 110 households categorized according to three livelihood strategies to identify the impacts of CEEs and driving factors affecting adaptation strategies. The innovative approach of this study is based on an estimation of the opinion of households about the impact they faced and the classification of livelihood strategies based on the income contribution of livelihood activities. This paper could serve as a reference for local governments proposing and implementing specific solutions attached to each livelihood strategy. Although our research produced some significant findings, there were some 
limitations. First, we applied the baselined research, leading to some indicators being very different from the average of the total population. Moreover, quite a small percentage of households were headed by females, so the data quality for the effect of this determinant was lower. The study also lacked some important indicators such as housing type and the adapting experience of households.

CEEs follow unpredictable trends. Statistics on CEEs (flooding, drought, typhoon, precipitation, and variability of temperature) show dramatic fluctuations, leading to difficulties in various activities, mostly in the agricultural sector. The impacts of CEEs brought back painful recollections, not only in the dimension of finances but also in terms of human loss. Many attempts to implement good collaboration among local communities that aimed at minimizing the impacts of CEEs and raising the adaptive capacity for farmers have achieved initial success; however, various barriers exist, such as the low ability of related officers, lack of local budgets, and shortage of new updated techniques for estimating, and mitigating the impacts of CEEs.

Our findings show that the majority of households did not implement an adaptation method (around 27\%), while nearly half of households applied the reactive adaptation method. The rest, around $28 \%$, implemented the proactive adaptation method. The application of the MLS model is suited to the aims of the study and could satisfactorily explain the factors affecting the decisions of households. Using 10 driving variables as input for the MLS model, we could explain $51.2 \%$ of the effects on adaptation strategy. Five driving variables could not explain household decision-making. Study findings also indicated the statistically significant driving factors in the choice of adaptation method. Households with a high birth rate tended not to implement any adaptation or adopted reactive adaptation. The households with a female head tended to be more active in implementing reactive adaptation. Next, several livelihood activities were correlated with the possibility of selecting an adaptation method; a model of proactive adaptation showed a better ability to explain than a no adaptation model. Moreover, a household that reported losses tended to apply a reactive or proactive adaptation method. In the same vein, proactive adaptation had a higher statistical significance than the reactive model, implying that the perception of households in terms of recognizing current and potential threats played a vital role. Last but not least, there was a difference in adaptation method based on different livelihood strategies. Households in the agri-based and mixed-based models were keen to implement reactive adaptation methods.

Recommendations are needed to improve the capacity of households to adopt appropriate methods for coping with CEEs. Raising awareness will show the importance of applying long-term adaptation methods, which will have better outcomes than short-term methods. Organizing training courses, not only in technical aspects but also in specific areas related to mitigation and reduction of and adaptation to CEEs, is essential [10]. Audience participation should be widespread, including not only heads of households but also members of the family who have a good education, allowing them to realize the potential threats of CEEs and be willing to propose and implement adaptation methods. There is a need to take women's viewpoints into account [10]. Moreover, local governments should find appropriate solutions to encourage strong collaborations between multiple stakeholders, especially organizations and households (a community-based approach) for good collaborative learning-discussing and sharing knowhow not only in terms of adapting to and reducing the impacts of CEEs but also for finding smart and sustainable economic strategies [5]. Long-term planning for adaptations to CC as well as CEEs should be a focus of local governments, which must then make action plans specific to the livelihood activities of different households [24].

Author Contributions: This study is a part of D.D.M.'s Ph.D. thesis and benefited from the valuable contributions of several authors. D.D.M. had the main duties of investigation, data curation, and original draft preparation of the manuscript; N.D.H. contributed to the conceptualization and methodology; P.L. helped with review and editing of the manuscript, visualization, and supervision. All authors have read and agreed to the published version of the manuscript.

Funding: This research received no external funding.

Conflicts of Interest: The authors declare no conflict of interest. 


\section{References}

1. Huynh, L.T.M.; Stringer, L.C. Multi-scale assessment of social vulnerability to climate change: An empirical study in coastal Vietnam. Clim. Risk Manag. 2018, 20, 165-180. [CrossRef]

2. Tian, Q.; Lemos, M.C. Household Livelihood Differentiation and Vulnerability to Climate Hazards in Rural China. World Dev. 2018, 108, 321-331. [CrossRef]

3. Beringer, A.; Kaewsuk, J.; Beringer, A.L.; Kaewsuk, J. Emerging Livelihood Vulnerabilities in an Urbanizing and Climate Uncertain Environment for the Case of a Secondary City in Thailand. Sustainability 2018, 10, 1452. [CrossRef]

4. Peng, L.; Xu, D.; Wang, X. Vulnerability of rural household livelihood to climate variability and adaptive strategies in landslide-threatened western mountainous regions of the Three Gorges Reservoir Area, China. Clim. Dev. 2019, 11, 469-484. [CrossRef]

5. Gustafson, S.; Joehl Cadena, A.; Ngo, C.C.; Kawash, A.; Saenghkaew, I.; Hartman, P. Merging science into community adaptation planning processes: A cross-site comparison of four distinct areas of the Lower Mekong Basin. Clim. Chang. 2018, 149, 91-106. [CrossRef]

6. Intergovernmental Panel on Climate Change (IPCC). Global Warming of $1.5^{\circ} \mathrm{C}$. An IPCC Special Report on the Impacts of Global Warming of $1.5^{\circ} \mathrm{C}$ above Pre-Industrial Levels and Related Global Greenhouse Gas Emission Pathways, in the Context of Strengthening the Global Response to the Threat of Climate Change; IPCC: Geneva, Switzerland, 2018.

7. Kartiki, K. Climate change and migration: A case study from rural Bangladesh. Gend. Dev. 2011, 19, 23-38. [CrossRef]

8. Abegaz, D.M.; Wims, P. Extension Agents' Awareness of Climate Change in Ethiopia. J. Agric. Educ. Ext. 2015, 21, 479-495. [CrossRef]

9. Altwegg, R.; Visser, V.; Bailey, L.D.; Erni, B. Learning from single extreme events. Philos. Trans. R. Soc. B Biol. Sci. 2017, 372. [CrossRef]

10. Miyan, M.A. Droughts in asian least developed countries: Vulnerability and sustainability. Weather Clim. Extrem. 2015, 7, 8-23. [CrossRef]

11. Ncube, M.; Madubula, N.; Ngwenya, H.; Zinyengere, N.; Zhou, L.; Francis, J.; Mthunzi, T.; Olivier, C.; Madzivhandila, T. Climate change, household vulnerability and smart agriculture: The case of two South African provinces. Jamba J. Disaster Risk Stud. 2016, 8, 182. [CrossRef]

12. Dung, T.C.; Minh, Đ.D. Assessing the adaptive capacity of households to climate change: A case study in quang dien district, thua thien hue province. Hue Univ. J. Sci. Econ. Dev. 2019, 128, 97-111. [CrossRef]

13. Anh, T.T.; Van, T.; Phong, G.; Tran, T.H.; Mulenga, M. Community Consultation for Long-Term Climate-Resilient Housing in Vietnamese Cities: A Comparative Case Study between Hue and Da Nang; Feasibility Study on Scaling up the Storm-Resilient Housing Model in Da Nang View Project Ph.D Research View Project; IIED: London, UK, 2018.

14. Van Huynh, C.; van Scheltinga, C.T.; Pham, T.H.; Duong, N.Q.; Tran, P.T.; Nguyen, L.H.K.; Pham, T.G.; Nguyen, N.B.; Timmerman, J. Drought and conflicts at the local level: Establishing a water sharing mechanism for the summer-autumn rice production in Central Vietnam. Int. Soil Water Conserv. Res. 2019, 7, 362-375. [CrossRef]

15. Smithers, J.; Smit, B. Human adaptation to climatic variability and change. Glob. Environ. Chang. 1997, 7, 129-146. [CrossRef]

16. Train, K.E. Discrete Choice Methods with Simulation; Cambridge University Press: Cambridge, UK, 2003; pp. 1-388.

17. Reidsma, P.; Ewert, F.; Lansink, A.O.; Leemans, R. Adaptation to climate change and climate variability in European agriculture: The importance of farm level responses. Eur. J. Agron. 2010, 32, 91-102. [CrossRef]

18. Minh, D.D.; Lebailly, P.; Hao, N.D.; Burny, P.; Hop, H.T.M. The dynamics of livelihood vulnerability index at farm household level: An empirical analysis of the coastal sandy zone in thua thien hue province, vietnam. Int. J. Econ. Financ. Issues 2019, 9, 77-89. [CrossRef]

19. Deressa, T.T.; Hassan, R.M.; Ringler, C.; Alemu, T.; Yesuf, M. Determinants of farmers' choice of adaptation methods to climate change in the Nile Basin of Ethiopia. Glob. Environ. Chang. 2009, 19, 248-255. [CrossRef] 
20. Okonya, J.S.; Syndikus, K.; Kroschel, J. Farmers' Perception of and Coping Strategies to Climate Change: Evidence From Six Agro-Ecological Zones of Uganda. J. Agric. Sci. 2013, 5, 252-263. [CrossRef]

21. Fosu-Mensah, B.Y.; Vlek, P.L.G.; MacCarthy, D.S. Farmers' perception and adaptation to climate change: A case study of Sekyedumase district in Ghana. Environ. Dev. Sustain. 2012, 14, 495-505. [CrossRef]

22. Below, T.B.; Mutabazi, K.D.; Kirschke, D.; Franke, C.; Sieber, S.; Siebert, R.; Tscherning, K. Can farmers' adaptation to climate change be explained by socio-economic household-level variables? Glob. Environ. Chang. 2012, 22, 223-235. [CrossRef]

23. Malik, A.S.; Smith, S.C. Adaptation To Climate Change in Low-Income Countries: Lessons From Current Research and Needs From Future Research. Clim. Chang. Econ. 2012, 3, 1250005. [CrossRef]

24. Kistner, E.; Kellner, O.; Andresen, J.; Todey, D.; Morton, L.W. Vulnerability of specialty crops to short-term climatic variability and adaptation strategies in the Midwestern USA. Clim. Chang. 2018, 146, 145-158. [CrossRef]

25. Intergovernmental Panel on Climate Change (IPCC). Impacts, Adaptations and Vulnerability; Contribution of Working Group II to the Fourth Assessment Report of IPCC on Climate Change; Cambridge University Press: Cambridge, UK, 2007.

26. Nguyen, A.D. Salt Intrusion, Tides and Mixing in in Multi-Channel Estuaries; Taylor \& Francis/Balkema: Boca Raton, FL, USA, 2008; ISBN 9780415471220.

27. Mcleod, E.; Poulter, B.; Hinkel, J.; Reyes, E.; Salm, R. Sea-level rise impact models and environmental conservation: A review of models and their applications. Ocean Coast. Manag. 2010, 53, 507-517. [CrossRef]

28. Syvitski, J.P.M.; Kettner, A.J.; Overeem, I.; Hutton, E.W.H.; Hannon, M.T.; Brakenridge, G.R.; Day, J.; Vörösmarty, C.; Saito, Y.; Giosan, L.; et al. Sinking deltas due to human activities. Nat. Geosci. 2009, 2, 681-686. [CrossRef]

29. Day, J.; Ibáñez, C.; Scarton, F.; Pont, D.; Hensel, P.; Day, J.; Lane, R. Sustainability of Mediterranean Deltaic and Lagoon Wetlands with Sea-Level Rise: The Importance of River Input. Estuaries Coasts 2011, 34, 483-493. [CrossRef]

30. Asian Development Bank (ADB). Anual Report. Improving Lives throughout Asia and the Pacific; ADB: Metro Manila, Philippines, 2014.

31. USAID. Country Overview.Climate Risk Profile Cambodia; USAID: Washington, DC, USA, 2019.

32. World Bank. The World Bank Annual Report 2010 In Review; World Bank: New York, NY, USA, 2010.

33. Bai, Y.; Deng, X.; Zhang, Y.; Wang, C.; Liu, Y. Does climate adaptation of vulnerable households to extreme events benefit livestock production? J. Clean. Prod. 2019, 210, 358-365. [CrossRef]

34. Rao, N. From abandonment to autonomy: Gendered strategies for coping with climate change, Isiolo County, Kenya. Geoforum 2019, 102, 27-37. [CrossRef]

35. Bitterman, P.; Bennett, D.A.; Secchi, S. Constraints on farmer adaptability in the Iowa-Cedar River Basin. Environ. Sci. Policy 2019, 92, 9-16. [CrossRef]

36. Ferdous, J.; Mallick, D. Norms, practices, and gendered vulnerabilities in the lower Teesta basin, Bangladesh. Environ. Dev. 2019, 31, 88-96. [CrossRef]

37. Hahn, M.B.; Riederer, A.M.; Foster, S.O. The Livelihood Vulnerability Index: A pragmatic approach to assessing risks from climate variability and change-A case study in Mozambique. Glob. Environ. Chang. 2009, 19, 74-88. [CrossRef]

38. Makate, C.; Makate, M.; Mango, N.; Siziba, S. Increasing resilience of smallholder farmers to climate change through multiple adoption of proven climate-smart agriculture innovations. Lessons from Southern Africa. J. Environ. Manage. 2019, 231, 858-868. [CrossRef]

39. Hao, D.N. Evolution of livelihood strategy of the households inthe coastal sandy zone of the North central region of Vietnam-Case study in Thua Thien Hue province. In Proceedings of the 2011 ASAE 7th International Conference, Hanoi, Vietnam, 13-15 October 2009.

40. People's committe Thua Thien Hue administrative map. Available online: https:/thuathienhue.gov.vn/ en-us/Home/General-Information/Admistrative-Map/tid/Administrative-map/cid/12B8E024-FAF2-4DBA84E4-A85400952C0D (accessed on 7 December 2018).

41. Obayelu, O.A.; Adepoju, A.O.; Idowu, T. Factors influencing farmers' choices of adaptation to climate change in Ekiti State, Nigeria. J. Agric. Environ. Int. Dev. JAEID 2014, 108, 3-16. 
42. Bryan, B.A.; Kandulu, J.M. Cost-effective alternatives for mitigating Cryptosporidium risk in drinking water and enhancing ecosystem services. Water Resour. Res. 2009, 45. [CrossRef]

43. Tazeze, A.; Haji, J.; Ketema, M. Climate Change Adaptation Strategies of Smallholder Farmers: The Case of Babilie District, East Harerghe Zone of Oromia Regional State of Ethiopia. J. Econ. Sustain. Dev. 2012, 3, 1-12.

Publisher's Note: MDPI stays neutral with regard to jurisdictional claims in published maps and institutional affiliations.

(C) 2020 by the authors. Licensee MDPI, Basel, Switzerland. This article is an open access article distributed under the terms and conditions of the Creative Commons Attribution (CC BY) license (http://creativecommons.org/licenses/by/4.0/). 